\title{
La Facultad de Teología de la Universidad de Navarra en su contexto (1966-1972)
}

\section{The University of Navarra's Faculty of Theology in its Context (1966-1972)}

\author{
Josep-Ignasi SARANYANA \\ Pontificio Comitato di Scienze Storiche \\ Città del Vaticano \\ ID ORCID 0000-0001-9306-6188 \\ jisaranyana@raed.academy
}

Resumen: La Facultad de Teología de la Universidad de Navarra es fruto del interés de San Josemaría Escrivá por la inserción de las ciencias sagradas en el mundo académico y por su enseñanza al más alto nivel. Aunque consideraba este tema desde los años treinta, la ocasión propicia se presentó con la reforma de los estudios universitarios propiciada por el Concilio Vaticano II. La Facultad nació, por tanto, en el marco de la recepción de los documentos conciliares y con el propósito de asumir «la discontinuidad en la continuidad» que supuso la asamblea conciliar. En consecuencia, su claustro académico se nutrió, desde el comienzo, de esa nueva atmósfera teológica, y dialogó con ella.

Palabras clave: Universidad de Navarra, Concilio Vaticano II, Teología postconciliar, Secularidad, Laicidad.
Abstract: The University of Navarra's Faculty of Theology is a fruit of Saint Josemaría Escrivá's desire of incorporating the sacred sciences in the academic realm and leveraging the impartation thereof. This issue significantly figured in his reflection since the 1930's, but the favorable occasion emerged following the reform of university studies ushered in by the Second Vatican Council. This Faculty was established, therefore, during the process of reception of the conciliar documents and intended to assume the «discontinuity in continuity» entailed by the Council. Consequently, this Faculty's members were immersed, from the very outset, in that new theological atmosphere and in dialogue with it.

Keywords: University of Navarra, Second Vatican Council, Postconciliar Theology, Secularity, Laicism. 


\section{El PRIMER SEXENIO DE la Facultad}

\section{a) La prehistoria}

E 1 fundador de la Universidad de Navarra y primer Gran Canciller, san Josemaría Escrivá, mostró desde la primera hora, es decir, al poco de recibir el carisma del Opus Dei, una notable valoración de la formación teológica. Ya en la Residencia DYA, la primera obra corporativa de apostolado de la Obra, previó la preparación religiosa de los estudiantes que allí se alojaban, y de quienes acudían a aquella casa por motivos diversos (estudio, dirección espiritual, para completar su formación académica por medio de clases de refuerzo, etc.), organizando cursos de doctrina católica ${ }^{1}$. Cuando se abrió la posibilidad de incardinar sacerdotes en la Obra, gestionó que los tres primeros fieles del Opus Dei, que se preparaban para las órdenes sagradas, tuvieran los mejores profesores de Teología que en aquel momento fue posible encontrar en Madrid ${ }^{2}$. Para ello constituyó formalmente, en diciembre de 1943, el Centro de Estudios Eclesiásticos de la Sociedad Sacerdotal de la Santa Cruz, que existió hasta 1947, en que se configuró diversamente, al recibir la Obra la aprobación como instituto secular.

Instalado en Roma definitivamente, mientras impulsaba la expansión de las labores apostólicas en nuevos países y dirigía la construcción de los edificios de la sede central en Viale Bruno Buozzi, procuró juntar en esas construcciones, todavía sin terminar y muy en precario, a un grupo numeroso de jóvenes de la Obra, laicos todos ellos y la gran mayoría con sus estudios universitarios terminados, para que cursaran estudios superiores de teología y derecho canónico en los ateneos pontificios romanos ${ }^{3}$.

${ }^{1}$ Cfr. González Gullón, J. L., DYA. La Academia y Residencia en la historia del Opus Dei (19331939), Madrid: Rialp, 2016, passim.

2 Cfr. Requena, F. M., «El claustro académico de Estudios Eclesiásticos de la Sociedad Sacerdotal de la Santa Cruz: los profesores de Teología de Álvaro del Portillo», Studia et Documenta 9 (2015) 13-55.

3 «El 29 de junio de 1948, cuando aún la expansión del Opus Dei estaba en sus inicios, Mons. Escrivá de Balaguer, que había fijado su residencia en Roma, erigió en esa ciudad el Colegio Romano de la Santa Cruz, como centro internacional de formación, destinado a miembros de la Sección de varones del Opus Dei provenientes de todos los países a los que el trabajo fuera extendiéndose. El 12 de diciembre de 1953 erigió el Colegio Romano de Santa María, centro análogo al anterior, pero destinado a la Sección de mujeres. El desarrollo de ambos centros fue rápido. De hecho, a mediados de los cincuenta, el ambiente del Colegio Romano de la Santa Cruz era ya manifiestamente internacional; poco después, lo fue también el del Colegio Romano de Santa María» (Fuenmayor, A. DE, GómeZ-IGlesias, V. e Illanes, J. L., El itinerario jurídico del Opus Dei. Historia y defensa de un carisma, Pamplona: Eunsa, 1989, 301-302). 
No sorprende, pues, que desde 1952, en que se inició el Estudio General de Navarra, se establecieran en él disciplinas de Teología para las distintas Escuelas. Y así, cuando el 5 de agosto de 1960 la Santa Sede erigió la Universidad de Navarra a partir del Estudio General, esas disciplinas se mantuvieron y potenciaron.

En la víspera de la clausura del Vaticano II, en concreto el 7 de diciembre de 1965, el arzobispo de Pamplona, monseñor Enrique Delgado Gómez, con sus sufragáneos de San Sebastián, Calahorra-Logroño y Jaca, solicitó al Gran Canciller de la Universidad de Navarra que en el seno de esa universidad se estableciera una Facultad de Teología ${ }^{4}$. El Gran Canciller acogió de buen grado la petición (que respondía, como se ha visto, a una antigua aspiración suya) y elevó tal solicitud a la recién constituida Conferencia Episcopal Española, la cual, en su primera asamblea plenaria de febrero de 1966, aprobó la petición de Josemaría Escrivá, trasladándola a la Santa Sede en diciembre de ese mismo año ${ }^{5}$.

La nueva institución teológica nacía al hilo del Concilio, con la pretensión, como objetivo próximo e inmediato, de «recibir» los riquísimos decretos y constituciones conciliares, aunque, evidentemente, no sólo para eso, sino con el propósito de perpetuarse en el tiempo, al servicio de la Iglesia.

\section{b) El Instituto de Teología}

En espera de la respuesta de la Santa Sede, el domingo 23 de abril de 1967 el Gran Canciller creó el Centro de Ciencias Eclesiásticas de la Universidad de Navarra, integrado por varios departamentos o institutos, entre los cuales el Instituto de Teología ${ }^{6}$. Ese mismo día se reunió con el arzobispo de

${ }^{4}$ Monseñor Enrique Delgado Gómez rigió la diócesis de Pamplona desde 1946 a 1968. Cuando la diócesis fue erigida como archidiócesis, en 1956, pasó a ser su primer arzobispo.

5 Illanes recuerda que, «en todo ese proceso, y en los años posteriores, estuvo presente don Álvaro del Portillo, como estrecho colaborador de san Josemaría» (ILLANES, J. L., «Mons. Álvaro del Portillo y las Facultades de ciencias eclesiásticas de la Universidad de Navarra», Scripta Theologica 46 [2014] 697-718, aquí 699).

${ }^{6}$ En el decreto de erección del Instituto de Teología se alude a su prehistoria: «Desde su fundación, la Universidad de Navarra ha cuidado con especial esmero la formación doctrinal religiosa de los alumnos. Para lograr que esa tarea fuera más profunda y más extensa, la Universidad de Navarra ha promovido además otras actividades complementarias de docencia e investigación teológicas, que han experimentado un continuo crecimiento» (GRAN CANCILLER DE LA UNIVERSIDAD DE NaVARRa, Decreto de erección del Centro de Ciencias Eclesiásticas de la Universidad de Navarra, 23 de abril de 1967. Fuente: Archivo General de la Universidad de Navarra). 
Pamplona y los tres sufragáneos, para informarles sobre las disposiciones que había tomado acerca de los estudios teológicos en la Universidad ${ }^{7}$. Pocas semanas después tuvo lugar una reunión de trabajo de los teólogos que habrían de constituir el primer claustro académico del Instituto ${ }^{8}$. Mientras tanto, habían comenzado las tareas de adaptación de un amplio local cedido con muchas facilidades por el Cabildo Catedral de Pamplona, con entrada por la Puerta Preciosa del claustro de la Catedral'.

Las clases comenzaron el martes 16 de octubre de ese año de 1967, con treinta alumnos matriculados, laicos y sacerdotes, mitad por mitad. Pocos días antes, el 5 de octubre, en unas declaraciones a la prensa, san Josemaría repetía su interés por la ciencia teológica:

«[...] la religión debe estar presente en la Universidad; y ha de enseñarse a un nivel superior, científico, de buena teología. Una Universidad de la que la religión está ausente, es una Universidad incompleta: porque ignora una dimensión fundamental de la persona humana, que no excluye -sino que exige- las demás dimensiones» ${ }^{10}$.

El claustro inicial de profesores del Instituto de Teología estuvo formado por Alfredo García Suárez (1927-1998), José Morales Marín y Amador García Bañón, dedicados a la Teología Fundamental; José María Casciaro Ra-

${ }^{7}$ Cfr. Diario de Navarra, 25 de abril de 1967, portada.

${ }^{8}$ Esas reuniones primeras tuvieron lugar en una residencia de profesores de la Universidad, sita en la Avenida Carlos III, 36, piso $6^{\circ}$, poco después de las fiestas sanfermineras de aquel año. Durante esas jornadas se perfiló el plan de estudios y los horarios, y se determinó el nombre de la futura revista, prevaleciendo Scripta Theologica sobre Acta theologica, que fue la otra propuesta. Las referencias cronológicas y anecdóticas que se consignan a continuación están tomadas del volumen de CALvo DE LAS Fuentes, J. Ma (ed.), Teología y Universidad. En el XXV aniversario de la Facultad de Teología de la Universidad de Navarra (1967-1992), Pamplona: Servicio de Publicaciones de la Universidad de Navarra, 1993.

9 Cfr. Diario de Navarra, de 30 de julio de 1967, 24, donde se informa de los trabajos de acondicionamiento de las «habitaciones cerca y sobre los claustros de la Catedral Metropolitana. Las obras iniciadas hace un mes tienen que estar terminadas para principios de octubre, fecha en que dará razón de vida la nueva Facultad. Las obras se encuentran en fase de derribo de tabiques. Las futuras aulas universitarias fueron en otro tiempo dormitorio de canónigos; actualmente era una edificación deshabitada y descuidada, a la derecha de la Capilla Barbazana, con ventanas y balcones sobre la Ronda del Obispo Barbazán». Se encargó de la reforma el arquitecto y catedrático Dr. Juan Lahuerta Vargas (1931-1992), y llevó las gestiones para conseguir los locales el Prof. Ismael Sánchez Bella, primer rector del Estudio General de Navarra y vicerrector de la Universidad, en 1967.

10 Entrevista publicada en Gaceta Universitaria (Madrid), en la fecha señalada, realizada por Andrés Garrigó y recogida después en Conversaciones con Mons. Escrivá de Balaguer, edición críticohistórica a cargo de ILLANES, J. L. y MÉNDIZ, A., Madrid: Rialp, 2012, 73c. 
mírez (1923-2004), Teodoro Larriba Urraca (1927-1996) y Miguel Gallart Ribera (1928-1995), docentes de Sagrada Escritura, a los que se añadió, por un tiempo, Juan Apecechea Perurena; Joaquín Ferrer Arellano (1931-2017), Pedro Rodríguez, Fernando Sánchez Arjona (1933-1985) y Agustín Arbeloa Egüés (1914-1997), encargados de Teología Dogmática; José María Martínez Doral e Ildefonso Adeva Martín, para Teología Moral; Javier Ibáñez Ibáñez y Lucas F. Mateo-Seco (1936-2014), responsables de Patrología y antigüedad cristiana; el liturgista Juan María Lecea Yábar; y Aurelio Fernández Fernández, que dictó Teología pastoral. Al año siguiente, es decir, en 1968, se incorporó, sustituyendo a Martínez Doral, el moralista Ramón García de Haro y Goytisolo (1931-1996).

La Junta Directiva del Instituto quedó constituida, en 1967, por Alfredo García Suárez, director; José María Casciaro, subdirector; Pedro Rodríguez, director de estudios; y Amador García Bañón, secretario.

El 1 de octubre de 1967 la Universidad contrató a Adolfo Castaño de León, primer auxiliar administrativo de la Facultad, que con el tiempo pasó a ser oficial de secretaría y terminó su recorrido profesional en la secretaría de la Facultad de Derecho, después de algunos años de trabajo en la Biblioteca de Humanidades. El primer bedel fue Donato Domínguez Jiménez († 2000) ${ }^{11}$.

\section{c) La Facultad de Teología y su primer claustro académico}

Para seguir con la sinopsis cronológica, el 1 de noviembre de 1969 la Congregación para la Educación Católica (con la expresa aprobación de Pablo VI) erigió la Facultad de Teología a partir del Instituto. Esta noticia fue comunicada personalmente por san Josemaría Escrivá a los profesores de la Facultad el 18 de noviembre, durante una breve estancia suya en Pamplona. Recordemos el testimonio de Amador García Bañón: «De la erección de la Facultad de Teología, el Fundador dejó una discreta constancia. Había encargado al arquitecto Manuel González-Simancas unas lámparas votivas de hierro forjado, para fijarlas en la pared del fondo de la ermita [del campus], a uno y otro lado de la imagen de la Madre del Amor Hermoso. El hoy Beato Josemaría entró en la ermita, besó los pies de la Virgen, rezó un Avemaría, y encendió las dos lámparas, que desde entonces permanecen continuamente

${ }^{11}$ Sólo doy las fechas biográficas de los que ya fallecieron. Las demás personas citadas, protagonistas de primera hora, viven todavía, gracias a Dios, cuando escribo estas líneas. 
encendidas. En cada portalámparas está grabada la misma leyenda: Rome, 1XI-1969. Laus Deo. Es la fecha de la erección [de la Facultad], en la solemnidad de Todos los Santos» ${ }^{12}$.

La Junta Directiva de la nueva Facultad quedó constituida, en 1969, por José María Casciaro, decano; Ramón García de Haro, vicedecano; Lucas F. Mateo-Seco, director de estudios; Amador García Bañón, secretario.

Alfredo García Suárez pasó a ser el primer director de Scripta Theologica, cuyo primer fascículo apareció en marzo de 1969, y José Morales fue secretario de la revista. La sede de la revista estaba en el campus, en la Biblioteca de Humanidades. Todos los trámites burocráticos los llevaba a cabo el Dr. Morales, hasta que en febrero de 1971 se incorporó Lourdes Ardanaz Ubani como administrativa, que poco duró allí, pues en junio de ese mismo año pasó a la secretaría de la Facultad, haciendo tándem con Adolfo Castaño.

En 1971 se integraron en el claustro académico los escrituristas Antonio García-Moreno y Virgilio Vegazo Sánchez (1933-2008), y el patrólogo Domingo Ramos-Lissón (1930-2016); y, un año después, los dogmáticos Jesús Sancho Bielsa y Luis Alonso-Martín, y el pastoralista Jesús Polo Carrasco (1930-1996).

Mientras tanto, en octubre de 1968 había comenzado su docencia el Instituto de Historia de la Iglesia, también encuadrado en el Centro de Ciencias Eclesiásticas de la Universidad de Navarra, con José Orlandis Rovira (19182010) como director, Gonzalo Redondo Gálvez (1936-2006) como subdirector, y Primitivo Tineo Tineo como secretario (a partir de 1970). Desde primera hora este Instituto contó con la colaboración del historiador José Goñi Gaztambide (1914-2002) y de otros especialistas. Con fecha 29 de septiembre de 1970, el Gran Canciller dispuso que «para coordinar mejor la labor docente y de investigación de la Facultad de Teología y del Instituto de Historia de la Iglesia [...] el Instituto de Historia de la Iglesia pas[ase] a depender directamente de la Facultad de Teología» ${ }^{13}$. De este modo, todos sus profesores se incorporaron al claustro de la Facultad.

Pocos meses después, en marzo de 1971, Escrivá de Balaguer escribía una entrañable carta a don Florencio Sánchez Bella, Vice-Gran Canciller de la

12 Teología y Universidad. En el XXV aniversario de la Facultad de Teología de la Universidad de Navarra (1967-1992), cit., 72b.

13 Gran Canciller de la Universidad de Navarra, Decreto de 29 de septiembre de 1970. Fuente: Archivo General de la Universidad de Navarra. 
Universidad, en la que expresaba, nada más comenzar, su alegría por el cumplimiento de un antiguo anhelo suyo:

«Por años he soñado con ese instrumento apostólico que es la Facultad de Teología de Navarra, y tengo una confianza ilimitada en que habrá de dar fruto abundante. Di, a esos hijos que trabajan allí, que espero tanto de su labor para la gloria de Dios y para el bien de la Iglesia Santa y de las almas; y que su tarea es de la más grande importancia, especialmente en las circunstancias actuales» ${ }^{14}$.

\section{d) Un plantel de jóvenes docentes salidos de las aulas}

Del Instituto de Teología se incorporaron como ayudantes, al claustro de la Facultad, algunos recién licenciados, mientras preparaban sus respectivas tesis doctorales: Teodoro López Rodríguez (1940-2007), que se dedicó a la Teología moral; Gonzalo Aranda Pérez (1943-2016), que se especializó en estudios bíblicos, muy en particular en el copto intertestamentario; Evencio Cófreces Merino (1941-2001), moralista, que pasó pronto al Instituto San Ildefonso de Toledo y fue deán del cabildo de esa catedral; Augusto Sarmiento Franco, también moralista y estudioso de la Escuela de Salamanca; Antonio Aranda Lomeña, dedicado a la Teología dogmática; y quien suscribe esta crónica, que se incorporó a la Junta Directiva de la Facultad en 1970 y se ha dedicado a la Historia de la Teología. Hubo, pues, seis vocaciones a la docencia, salidas de la primera promoción, a las cuales se sumaron el escriturista Santiago Ausín Olmos, el patrólogo Pio G. Alves de Sousa, después consagrado obispo en Portugal, y el historiador-teólogo Juan Belda Plans, procedentes de la tercera promoción; el biblista Claudio Basevi, de la cuarta; y el patrólogo Marcelo Merino Rodríguez, de la quinta. De esta forma, la Facultad comenzó a nutrirse de sus propios alumnos. Años más tarde, José María Calvo de las Fuentes, antiguo alumno de la primera promoción y también periodista, se agregó a la Facultad como jefe del gabinete de prensa.

En el curso 1969/70 se matricularon las primeras alumnas, todas ellas ya en posesión de un título universitario superior: Mercedes Otero Tomé,

${ }^{14}$ Gran Canciller de la Universidad de Navarra, Carta a Florencio Sánchez Bella, de 27 de marzo de 1971. Fuente: Archivo General de la Universidad de Navarra. 
Isabel María Sánchez Sánchez (1944-1978) y María de la Capilla Caracuel Tubio, que se licenciaron en Teología en 1971 y posteriormente se doctoraron las dos primeras, en 1973. En el curso de 1971/72 se inscribieron en licenciatura cuatro alumnas: Josephine Ti-Ti Chen (1931-2005), nacida en Beijing y naturalizada norteamericana, la italiana Maria Caterina Calzona y las españolas Matilde López Vigil y Concepción Rodríguez García, doctorándose las tres primeras.

A finales de verano de 1971, el Gran Canciller de la Universidad, que seguía con prudente atención el desarrollo de la Facultad, remitió una nota a ese centro, con el encargo de preparar una edición de la Sagrada Biblia (bilingüe latín-castellano), con abundantes notas basadas en la multisecular tradición de la Iglesia. La nota, trasmitida por el Rectorado, empezaba con unas palabras, que eran mucho más que un programa de investigación, porque apuntaban a la idea de Universidad y expresaban, en términos generales, la esencia del quehacer universitario:

$\ll 1$. No es ajeno a una facultad universitaria difundir material para la cultura del pueblo. No se puede olvidar que los fines de las universidades son: conseguir que un grupo reducido se puedan dedicar con fruto a la investigación; formar otro grupo mayor de profesionales para la docencia; lograr que la casi totalidad de sus alumnos sea capaz de hacer, después de terminados sus estudios, un servicio a la sociedad.

2. Las facultades de teología no son una excepción: y, dentro de ellas, las secciones de Sagrada Escritura deben preocuparse de profundizar en los estudios bíblicos, preparando investigadores y profesores, y ofreciendo a todos los estudiosos buenas ediciones, con el conveniente y más hondo aparato crítico, de los libros sagrados: y, al pueblo, ediciones populares.

3. Es justo, en efecto, que las facultades eclesiásticas contribuyan a fortalecer la formación doctrinal y la piedad de los fieles, haciendo publicaciones de la Sagrada Escritura, con las notas necesarias, para aumentar la cultura religiosa del pueblo. $[\ldots ..] \gg^{15}$.

Esta Biblia debía reunir, por tanto, dos requisitos: seriedad científica y lenguaje asequible. El encargo, que respondía a las prioridades manifestadas

${ }^{15}$ Nota del Rectorado de la Universidad de Navarra a la Facultad de Teología, de 16-IX-1971. Fuente: Archivo General de la Universidad de Navarra. 
por el Vaticano II, al auspiciar la vuelta a las fuentes como fundamento de toda sana especulación teológica, fue pilotado desde el primer momento por el Prof. José M. Casciaro y tardó más de veinticinco años en culminarse ${ }^{16}$. No obstante, los efectos positivos de esta investigación sobre la docencia de la Facultad se advirtieron ya al poco tiempo.

Como este proyecto se sale por completo de las coordenadas temporales de nuestro estudio y merecería una atención amplia y detenida, lo dejo ahora de lado.

\section{e) Marco jurídico-canónico del momento}

El proceso institucional, que acabo de describir, culminó con la redacción de los estatutos del nuevo centro académico, una tarea en la que se implicaron unos cuantos profesores durante varios meses, con el asesoramiento de la Cancillería y de la Facultad de Derecho Canónico ${ }^{17}$. Conviene decir dos palabras sobre este asunto, en el que la Facultad de Teología procuró atenerse en todo a las directivas de la Santa Sede y al espíritu del Concilio.

El decreto Optatam totius del Vaticano II, sobre la formación sacerdotal, aprobado el 25 de octubre de 1965, había dedicado el capítulo quinto a señalar algunas directrices para la «revisión de los estudios eclesiásticos». Exigía que los seminaristas, al emprender sus estudios, tuvieran una formación semejante a la que se pedía para iniciar los estudios superiores o universitarios, y que su conocimiento de la lengua latina les permitiera manejar las fuentes eclesiásticas. También señalaba que en el plan de estudios debían coordinarse filosofía y teología.

Esta última recomendación era importante, porque apuntaba a una anterior separación entre ambas disciplinas, que debía subsanarse. Es obvio -recordaba el Concilio- que filosofía y teología son ciencias distintas por su objeto; sin embargo, la autonomía de la filosofía no debía exagerarse hasta tal extremo, que los candidatos al sacerdocio fuesen óptimos conocedores de la historia de la filosofía, pero fideístas al cabo, como si la racionalidad filosófica no fuera un momento interno del buen hacer teológico: «Las disciplinas

${ }^{16}$ Cfr. Teología y Universidad. En el XXV aniversario de la Facultad de Teología de la Universidad de Navarra (1967-1992), cit., 186-188. En estas páginas se informa del estado del proyecto en 1992.

${ }^{17}$ Los estatutos fueron aprobados ad tempus por la Sagrada Congregación para la Educación Católica, el 4 de diciembre de 1975. 
filosóficas hay que enseñarlas de suerte que los alumnos se vean como llevados de la mano ante todo a un conocimiento sólido y coherente del hombre, del mundo y de Dios, apoyados en el patrimonio filosófico siempre válido [...] de forma que los alumnos, bien conocida la índole de la época presente, se preparen oportunamente para el diálogo con los hombres de su tiempo» (OT, n. 15).

A continuación, el Concilio animaba a formar críticamente a los estudiantes, para que pudieran retener la verdad de los sistemas filosóficos y rechazar sus errores. Evocaba que la teología se ha de enseñar a la luz de la fe; mencionaba la importancia de una buena formación bíblica; invitaba a conocer bien la historia del dogma y de la teología; insistía en seguir las enseñanzas de Santo Tomás, especialmente en teología dogmática; y, finalmente, aconsejaba el perfeccionamiento de la teología moral, «cuya exposición científica [debe estar] más nutrida de la doctrina de la Sagrada Escritura» (OT, n. 16).

Todo lo dicho, al hilo de Optatam totius, debe entenderse a la luz de la pretensión del Vaticano II, distinta de la que tuvo el primer Vaticano, pendiente, más bien, de la concordancia y armonía entre la fe y la razón, que de las relaciones de la Iglesia con el «mundo moderno». El Vaticano II, en efecto, no se enfrentaba ni al racionalismo ni al fideísmo cultural, sino a la postmodernidad, es decir, a una especie de aversión hacia la condición razonable de la fe. La teología no debe ser, por tanto, un mero anuncio del Evangelio, sino una elaboración científica, que pide la colaboración de la filosofía. La aversión a la filosofía, con el pretexto de no contaminar el genuino espíritu de los comienzos, tiene raíces luteranas. Cuando redacto estas líneas, me viene a la memoria, la crítica de Martin Heidegger a la teología dialéctica de Karl Barth, calificándola de «fantasmada», como «una explosión con muchos cascotes y mucho humo» ${ }^{18}$.

Bajo la guía de Optatam totius, y secundando un mandato del Vaticano II, expresado en la declaración Gravissimum educationis ${ }^{19}$, la Santa Sede se apresuró a redactar una nueva regulación de los estudios eclesiásticos. En muy poco

${ }^{18}$ Grossmann, A. y Landmesser, Ch. (eds.), Rudolf Bultmann / Martin Heidegger. Correspondencia. 1925-1975, trad. esp. de GABÁs, R., Barcelona: Herder, 2011, 56. La carta de Martin Heidegger a Rudolf Bultmann es de 19 de marzo de 1927.

19 Esta declaración es de 28 de octubre de 1965. Cfr. especialmente los nn. 10 y 11, dedicados a las Facultades y Universidades Católicas y a las Facultades de Ciencias Sagradas. 
tiempo, la Congregación para la Educación Católica preparó unas Norme quedam ad constitutionem apostolicam Deus scientiarum Dominus de studiis academicis ecclesiasticis recognoscendum, promulgadas el 20 de mayo de 1968. Como indica el título del documento, al que se llegó después de una amplia consulta a todas las instituciones docentes de carácter eclesiástico entonces existentes en el mundo, fueron aprobadas ad experimentum unas disposiciones para adecuar la constitución Deus scientiarum Dominus, de 24 de mayo de 1931, a la espera de redactar un documento definitivo con más calma ${ }^{20}$. Por ello, las Norme quedam adjuntaban, como anexo, la constitución de Pío XI. La regulación definitiva vendría varios años después, el 15 de abril de 1979, con la constitución apostólica Sapientia christiana.

A la estela de las Norme quedam proliferaron los centros superiores de ciencias sagradas, al tiempo que los nacidos al amparo de la constitución Deus scientiarum Dominus, de 1931, procuraron adaptarse a los nuevos aires. Fueron los años del esplendor y máxima popularidad de la teología y del estrellato de los más destacados cultores de tales disciplinas ${ }^{21}$. En España se crearon (o se remodelaron) ocho Facultades de Teología, tres de ellas con dos sedes (en total, once centros superiores dedicados a estas enseñanzas), más dos Facultades de Derecho Canónico.

Conviene rememorar, por último, que el Concilio supuso, como la crítica histórica ha destacado, una continuidad y, al tiempo, una discontinuidad. En esto consistió la verdadera reforma propuesta por la asamblea conciliar ${ }^{22}$. Por ello, la teología que debían desarrollar los teólogos de la Universidad de Navarra debía responder a tales criterios; y a fe que lo consiguieron, como se mostrará a continuación.

${ }^{20}$ Las Norme quedam, que son muy breves (sólo cincuenta números), afirman con gran nitidez el carácter científico de la teología, de acuerdo con el concepto moderno de ciencia (es decir, atendiendo al rigor crítico e histórico, y a la especialización); enfatizan al diálogo de la fe con la comunidad científica internacional; y subrayan también la finalidad evangelizadora y pastoral del quehacer teológico.

21 Sobre el itinerario de las Norme quedam hasta llegar a la constitución apostólica Sapientia Christiana, cfr. Illanes, J. L., Teología y Facultades de Teología, Pamplona: Eunsa, 1991, passim.

22 Benedicto XVI, en un célebre discurso a la curia romana, de 22 de diciembre de 2005, abordó la cuestión de la continuidad y discontinuidad del Concilio, saliendo al paso de la «hermenéutica de la ruptura», a la que opuso la «hermenéutica de la reforma», es decir, la discontinuidad en la continuidad. El planteamiento de Benedicto XVI causó un gran impacto y ha marcado un antes y un después al considerar la verdadera novedad conciliar. Trató nuevamente el tema en un inédito autobiográfico de 2 de agosto de 2012, publicado en L'Osservatore Romano al cabo de unos meses (11 de octubre de 2012). 


\section{La Facultad de la Universidad de NavarRa EN SU CONTEXTO TEOLÓGICO}

\section{a) Una iniciativa en tiempos turbulentos}

A pesar del entusiasmo de los promotores, impulsados por el Gran Canciller de la Universidad, y de los objetivos institucionales y académicos alcanzados en tan poco tiempo, «el momento era el menos oportuno para que una Facultad [de Teología] comenzara su andadura», como reconocía Pedro Rodríguez años después:

«En la Iglesia [...] las calles estaban levantadas y era muy conflictivo caminar. Pienso que, en resumidas cuentas, lo que había era una gran batalla, y no sólo intelectual, por la interpretación del Concilio. Sustancialmente -aunque los matices cambien y los contextos- la misma que se ha venido prolongando en estos 25 años [hasta 1992]: una lucha entre una interpretación secularizante y horizontalista y otra minimalista y conservadora. Abrirse paso entre ellas era y es muy costoso. Pero entonces, recién terminado el Concilio y cuando se estaban dando los primeros pasos para su aplicación, la cosa tendía a agravarse y a hacerse cada vez más dura. [...]. Nosotros teníamos, gracias a Dios, muy claro que la Teología que hacía falta en la Iglesia, no era una teología manualística, inmovilista y rígida -llamémosla entre comillas preconciliar- sino una teología inspirada en el Vaticano II, pero siguiendo una interpretación fiel al Concilio mismo y a las directrices que para la lectura del Concilio iba dando el Papa Pablo VI. En realidad, era esto lo que me explicó Monseñor Escrivá de Balaguer [en enero de 1967]: él esperaba de nosotros una Teología abierta a la nueva sensibilidad, pero indiscutiblemente fiel al Magisterio de la Iglesia ${ }^{23}$.

Convenía entrar en los temas debatidos, pero andar con mucho tiento. San Josemaría Escrivá lo había subrayado en 1971, en la ya citada carta al Dr. Florencio Sánchez Bella:

«Siempre he defendido y defenderé la libertad de mis hijos y la de todos los cristianos, en las muchas cosas que son opinables. Pero, a la

${ }^{23}$ Rodríguez, P., Teología y Universidad. En el XXV aniversario de la Facultad de Teología de la Universidad de Navarra (1967-1992), 58b. 
vez, he recordado y recordaré a todos que esa libertad requiere responsabilidad: muy especialmente cuando está en juego la salvación de las

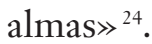

Se conserva un testimonio del programa teológico que se proponía aquel entusiasta primer equipo académico. Sin embargo, antes de analizarlo repasemos algunos hitos de la situación teológica del conflictivo momento, para contextualizar debidamente el citado proyecto.

\section{b) Las relaciones entre el Magisterio y los teólogos, en tres actos}

Una revista teológica agrupó, en los años inmediatos al Vaticano II, las más destacadas firmas de las ciencias sagradas, entre las cuales muchos peritos de la asamblea conciliar. Fue la revista Concilium, fundada en 1965 por Antonie van den Boogaard, Paul Brand, Yves Congar, Hans Küng, JohannBaptist Metz, Karl Rahner y Edward Schillebeeckx. Esta publicación, de carácter internacional, se lanzó en siete lenguas y en once ediciones nacionales. Su difusión e influencia fue muy notable, pero pronto derivó hacia posiciones críticas con relación al magisterio pontificio. En 1972, algunos miembros del consejo de redacción de Concilium se separaron, agrupándose con otros teólogos de su mismo parecer, para fundar la revista Communio, también de carácter internacional y editada en muchas lenguas, pero de orientación más «romana», por así decir. Deben recordarse sus promotores: Hans Urs von Balthasar, Joseph Ratzinger, Henri de Lubac y Walter Kasper.

Entre las dos fechas señaladas (1965 y 1972) ocurrieron una serie de hechos, de los que daré somera noticia. Las ideas implicadas en los acontecimientos rememorados no podían no gravitar en los primeros pasos teológicos de la nueva Facultad. En toda crisis hay elementos positivos entretejidos con desarrollos desbocados. Convenía separar el oro de la ganga, y que los estímulos fecundos no quedaran apagados por las turbulencias del momento.

${ }^{24}$ Gran Canciller de la Universidad de Navarra, Carta a Florencio Sánchez Bella, de 27 de marzo de 1971. Fuente: Archivo General de la Universidad de Navarra. 


\section{Primer acto: Magisterio versus oficio teológico}

Las relaciones de algunos peritos conciliares con el magisterio pontificio se enturbiaron en poco tiempo. El protagonismo que habían tenido los peritos en la elaboración de los documentos (cosa normal, por otra parte, pues lo mismo había ocurrido en el Concilio de Trento y en el Vaticano I), provocó en el inmediato postconcilio que algunos teólogos se considerasen como una instancia autónoma y paralela al magisterio papal. Pablo VI intentó reconducir esa dificultad auspiciando un magno Congreso de Teología del Vaticano II, que tuvo lugar en Roma del 26 de septiembre al 1 de octubre de 1966. El congreso fue convocado por los rectores de las Pontificias Universidades y Ateneos de la Urbe, bajo la presidencia de Édouard Dhanis, rector de la Gregoriana.

Poco antes de la apertura, el 21 de septiembre, Pablo VI envió una carta al cardenal Giuseppe Pizzardo, en que subrayaba la importancia de ese encuentro teológico, destacaba la armonía que había presidido su preparación (aludiendo veladamente a las rivalidades que durante el concilio se habían advertido entre el Laterano y otras Universidades Pontificias, ya superadas, al menos en apariencia) y recordaba que el evento debía contribuir a la recepción de los documentos conciliares. El Romano Pontífice concedía un gran relieve al oficio de los teólogos y manifestaba una gran estima por su labor. El trabajo y la reflexión teológica debían desempeñar una función mediadora entre el Concilio y los fieles. Y destacaba también que los teólogos, adecuadamente preparados para desarrollar esa función, debían trabajar siempre bajo la guía del magisterio eclesiástico ${ }^{25}$.

El tema general del congreso fue «La Teología del Concilio Vaticano II», que se dividió en diez secciones: misterio de la Iglesia; colegio episcopal y origen del oficio episcopal; María y la Iglesia; presencia del Señor en la comunidad de culto; el deber misionero esencial de la Iglesia y la relación con religiones no cristianas; concepto teológico de historia de la Salvación; el misterio de la Sagrada Escritura y de la Tradición; la libertad religiosa; el fundamento teológico del diálogo de la Iglesia con el mundo; y el ecumenismo.

Ante una numerosísima concurrencia, hubo diecisiete ponencias y 56 comunicaciones, con la participación de los peritos más renombrados del Vati-

25 «Patet igitur, quanti aestimandae sint muneris partes theologiæ cultoribus tribuendæ, quippe qui sub ductu ecclesiastici magisterii præ ceteris idonei sint ad huiusmodi investigationis opus rite peragendum» (PABLO VI, Epistula Cum iam, de 21 de septiembre de 1966). 
cano II. Allí disertaron Pietro Parente, Carlo Colombo, Henri de Lubac, Edward Schillebeeckx, Karl Rahner, Aimé-Georges Martimort, Pierre Benoit, Courtney Murray, Ives-Marie Congar, Jean Daniélou, Marie-Dominique Chenu, Joseph Ratzinger y un largo etcétera, entre ellos los españoles Antonio María Javierre, Joaquín Salaverri, Teodoro Jiménez Urresti, José Antonio Aldama y Juan Alfaro.

En cuanto a la elección de los temas, tanto Joaquín Losada como Pedro Rodríguez, cronistas destacados del evento, señalaron la ausencia del tema del laicado, que había sido precisamente una de las cuestiones centrales del Vaticano II ${ }^{26}$. Lo constataba Alfredo García Suárez, en una intervención durante el congreso, al señalar que «cuando se habla de las relaciones dialógicas de la Iglesia con el mundo se restringe con demasiada frecuencia la Iglesia a la sociedad oficial y estructuralmente religiosa (jerarquía), olvidando que la Iglesia es, además, una comunión de vida teologal cuyas manifestaciones no son necesariamente de carácter religioso; con ello se continúa contemplando a los laicos casi exclusivamente como instrumentos colaboradores de la Jerarquía, lo que desnaturaliza la dinámica cristiana del Pueblo de Dios al impedir el paso decisivo dado por el Concilio [Vaticano II] acerca de la autonomía de los laicos en la inspiración cristiana del mundo» ${ }^{27}$. Es un tema que García Suárez meditaba mucho por aquellas fechas, como se verá más adelante. Pedro Rodríguez lamentaba, además, la ausencia de una teología del sacerdocio y de una «teologia de religiosis», que intentase explicar teológicamente qué puesto ocupan los religiosos en el Pueblo de Dios.

Según Illanes, «la importancia reconocida a la Teología, sea en general, sea en orden al diálogo con el ambiente, la cultura y la mentalidad contemporánea, debía llevar, casi necesariamente, a plantear la cuestión de sus relaciones con el Magisterio en cuanto tarea eclesial» ${ }^{28}$. Y a tal cuestión dedicó Pablo VI su discurso de clausura, que fue el momento mayor del congreso ${ }^{29}$. Magisterio y teología, dijo el Papa, coinciden por tener una raíz común (ambos parten de

${ }^{26}$ Losada Espinosa, J., «Congreso Internacional del Concilio Vaticano II», Razón y Fe 174 (1966) 455-466; y RodrígueZ, P., «El Congreso de Teología del Vaticano II», Palabra 15 (1966) 19-24.

27 Intervención recogida por RodRíGUEZ, P., en su crónica: «El Congreso de Teología del Vaticano II», cit.

${ }^{28}$ ILlanes, J. L., «Teología y método teológico en los documentos del Concilio Vaticano II», Scripta Theologica 12 (1980) 761-787.

29 Pablo VI, Discorso ai participanti al Congreso Internazionale di Teologia del Concilio, 1 de octubre de 1966. 
la Revelación) y una finalidad también común (pues están al servicio del mismo fin, o sea, conservar, exponer, enseñar y defender el sagrado depósito de la Revelación). Pero difieren en que tienen funciones y medios diversos.

La función de la teología es triple, recordó el Papa: conocer e investigar del modo más completo las verdades reveladas; dar a conocer a la comunidad cristiana y particularmente al Magisterio, los frutos de sus investigaciones; y finalmente tratar de difundir, ilustrar, justificar y defender la verdad autoritativamente declarada por el Magisterio. El magisterio, en cambio, tiene ante todo la misión de transmitir y testimoniar la doctrina recibida de los Apóstoles; le compete juzgar con autoridad, a la luz de la Revelación, acerca de las nuevas doctrinas y de las soluciones propuestas por la teología; y, por último, debe proponer con autoridad aquellas nuevas explicaciones o acomodaciones de la Revelación a los tiempos presentes, bajo la guía del Espíritu Santo.

Por consiguiente, el magisterio es una instancia de carácter carismático; mientras que la teología procede al modo humano, con la fuerza o capacidad analítica, discursiva e investigadora. El Magisterio habla con autoridad divina; la teología, en cambio, con autoridad humana. Dicho en términos más precisos, la teología ocupa una posición intermedia entre la fe de la Iglesia y el Magisterio, con vistas a la formación del pueblo fiel ${ }^{30}$.

De esta dura y difícil controversia entre teólogos y magisterio, que en su momento agitó mucho los ánimos, hay un testimonio primerizo en Scripta Theologica, redactado por José Morales. Su trabajo se publicó en el segundo volumen de la revista y, al cabo de los años, merece la pena releerlo, como testigo de la atención que la Facultad de Navarra prestaba al debate internacional $^{31}$. Es una reflexión sobre la infalibilidad de la Iglesia (in credendo), con abundantes referencias bibliográficas, desde los clásicos Juan de Torquemada y Melchor Cano, pasando por la teología del XIX (John Henry Newman, Matthias Joseph Scheeben, Johann Baptist Franzelin), hasta los peritos del Vaticano II (como Karl Rahner, Yves-Marie Congar y Jean Daniélou). En el trasfondo, el revuelo protagonizado por Hans Küng y su monografía Die Kirche, publicada en 1967 y, más en concreto, su ruidoso ensayo Unfehlbar? Eine

$30 \ll$ La Teologia adempie ancora un'altra funzione rispetto al Magistero: è mediatrice del suo insegnamento per la formazione della fede e del costume morale nel popolo cristiano. Essa è, in certa misura, mediatrice tra la fede della Chiesa e il Magistero» (PABLO VI, Discorso ai participanti al Congreso Internazionale di Teologia del Concilio, cit.).

31 Morales, J., «Nota histórico-doctrinal sobre las relaciones entre magisterio eclesiástico, oficio teológico y sentido popular de la fe», Scripta Theologica 2 (1970) 481-499. 
Anfrage, aparecido en ese mismo año de 1970. Pedro Rodríguez también trató el tema en la revista de la Facultad, aunque más tangencialmente ${ }^{32}$.

\section{Segundo acto: $E l$ «Catecismo bolandés»}

A los nueve días de la terminación del congreso «La Teología del Concilio Vaticano II», apareció en Holanda el Nuevo Catecismo para adultos, preparado por el Instituto Superior de Catequética de Nimega ${ }^{33}$. En noviembre de 1966 un grupo de católicos holandeses se dirigió a Pablo VI expresando su desasosiego por algunas afirmaciones del Catecismo. En abril de 1967 se reunió una comisión mixta paritaria de teólogos (unos escogidos por la Santa Sede y otros por el episcopado holandés ${ }^{34}$ ), que no llegó a un acuerdo. El Papa designó entonces una comisión cardenalicia, que presentó, en diciembre de 1967, unas propuestas de mejora del texto catequético. Una comisión de teólogos (dos por parte de la Santa Sede y dos holandeses, quedando al final sólo uno holandés, porque el otro no quiso intervenir) se reunió para desarrollar técnicamente las sugerencias de los cardenales. El 14 de marzo de 1968 la Santa Sede envió al Instituto Catequético de Nimega el texto preparado por los tres teólogos. Después de un largo silencio, el 10 de junio de 1968 los autores del Catecismo respondieron a los obispos holandeses, que «hemos llegado juntos a la conclusión unívoca de que las propuestas [de correcciones], tanto tomadas singularmente como en su conjunto, deben ser rechazadas». A los pocos días, el 30 de junio, Pablo VI pronunciaba una solemne Profesión de fe, conocida con el nombre de Credo del Pueblo de Dios, que de alguna manera tomaba en consideración y aclaraba los puntos débiles del Catecismo, aunque las pretensiones de ese símbolo tenían mayor alcance.

Los puntos del texto holandés que ofrecían ambigüedades y debían ser corregidos, se referían a la existencia de espíritus puros (ángeles y demonios);

32 RodrígueZ, P., «Misterio y comunidad. Estudio de sus relaciones en orden a la fundamentación de una teología del ministerio eclesiástico», Scripta Theologica 2 (1970) 119-142.

33 Tengo a la vista la traducción castellana (de la segunda edición holandesa), publicada por Herder, Barcelona 1969, que lleva un cuadernillo anejo titulado: Suplemento al Nuevo Catecismo para adultos. Enmiendas y adiciones al Catecismo holandés, redactadas según las indicaciones de la Comisión Cardenalicia, Barcelona: Herder, 1969. Véase también: Las correcciones al Catecismo holandés. Suplemento al Nuevo Catecismo, texto redactado por Dhanis, É., Visser, J. y Fortmann, H. J., Madrid: BAC, 1969 (con complementos de Pozo, C.).

${ }^{34}$ Entre los «holandeses» se hallaban el dominico Edward Schillebeeckx y el jesuita Piet Schoonenberg, autores intelectuales del Catecismo, sobre todo el segundo. 
la espiritualidad del alma y su creación inmediata por Dios; el pecado original (realidad y transmisión); la perpetua virginidad de Santa María; la plena satisfacción de la pasión, muerte y resurrección de Nuestro Señor Jesucristo; el sacrificio de la Cruz, perpetuado en el sacrificio eucarístico; la presencia real y la conversión eucarística (substancial); la infalibilidad de la Iglesia (in credendo) y la cognoscibilidad, aunque limitada, de los misterios sobrenaturales; el sacerdocio ministerial (distinto esencialmente del sacerdocio común de los fieles) y el ministerio petrino; algunos puntos de teología dogmática (sobre la Santísima Trinidad, las ciencias del alma de Cristo, la virtualidad de algunos sacramentos, la escatología intermedia, etc.); y otros asuntos de teología moral (la universalidad de las leyes morales, la indisolubilidad del matrimonio, la distinción entre pecados mortales o graves y veniales, etc.).

Si se leen con atención los temas debatidos y las correcciones propuestas por la Santa Sede, se advierte que los asuntos discutidos eran de gran calado, algunos ya resueltos por la tradición de la Iglesia y otros todavía abiertos a la especulación teológica y pendientes de clarificación. No extraña, pues, que los teólogos holandeses se planteasen algunas de esas cuestiones. Sin embargo, resultaba inoportuno que tales hipótesis, todavía muy provisionales y en algunos casos indebidas, saltasen a la calle impresas en un «catecismo». Las discusiones deben mantenerse en los cenáculos especializados, como siempre se ha hecho, distinguiendo entre el ámbito de los especialistas y el mundo de la predicación y de la pastoral. También la ciencia teológica tiene sus reglas deontológicas, a las que debe sujetarse el teólogo ${ }^{35}$.

De las cuestiones suscitadas por el Nuevo Catecismo encontramos algún eco en las publicaciones de los profesores de la Facultad de Teología. José Morales ya había tratado el tema de la infalibilidad in credendo de la Iglesia, como

35 Santo Tomás abordó tres veces la responsabilidad moral del teólogo: en su Quodlibeto tercero (q. 4, a. 2); en su comentario al De Trinitate boeciano (In Boëthii de Trinitate, q. 2, a. 4c); y en la Summa theologice, prologus totius Summe. Distingue entre el hablar y el escribir. En cuanto al hablar, estima que es mejor callar cuando los misterios manifestados darían lugar a irrisión, por ejemplo, al comunicarlos a los «infieles» (es decir, a los no cristianos); y considera que también es prudente callar, cuando las cosas son tan sutiles, que podrían equivocar a los «rudos» (a los creyentes que tienen menos formación), aun cuando estuviesen dispuestos con la mejor voluntad a acogerlas. En cuanto al escribir y publicar: «Al escribir no se puede hacer tal distinción [entre infieles y rudos], porque los libros pueden caer en manos de cualquiera y, por tanto, las cosas [muy sutiles] se han de ocultar con la oscuridad de las palabras, para que de ese modo sean útiles a los sabios que las entienden, y queden ocultas a los simples [o rudos] que no las pueden comprender. De este modo, no se molesta a nadie, porque los que entienden se entretienen en la lectura y, en cambio, los que no comprenden no están obligados a leer». 
se ha dicho, al hablar de las relaciones entre el magisterio eclesiástico y la teología ${ }^{36}$. Además, Aurelio Fernández publicó una nota breve y bien documentada sobre la distinción entre el sacerdocio común y el sacerdocio ministerial, también discutida por Nuevo Catecismo; un tema de gran trascendencia, no sólo sacramental y eclesiológica, sino también jurídica y pastoral, si se recuerda el importante debate acerca de la distinción entre el ministerio de los presbíteros y la condición laical, de los años treinta y cuarenta, al reflexionar sobre la condición de los seglares adscritos a la Acción Católica ${ }^{37}$. Interesa aquí destacar una de sus conclusiones. Después de repasar el iter redaccional de Lumen gentium y de Apostolicam actuositatem, afirma: «Y si es cierto que la formulación dogmática es el fin de una especulación racional, es, al mismo tiempo, el comienzo de una reflexión teológica que trata de captar la riqueza de Dios encerrada en la verdad definida. En la doctrina del Vaticano II sobre el sacerdocio de los fieles se impone una más profunda reflexión, ya que no se trata de una fórmula de fe, sino de una mera afirmación doctrinal, aunque gravite sobre ella el peso de un Concilio Ecuménico. Pero esta reflexión ha de partir siempre de la distinción in essentia del sacerdocio jerárquico». (Aurelio Fernández se quedó entonces quizá un poco corto, en sus calificaciones doctrinales, aunque vislumbró que la cuestión debía analizarse con mayor profundidad).

\section{Tercer acto: la discusión sobre la libertad de investigación teológica}

Dos años después del Nuevo Catecismo apareció, en la revista Concilium, la polémica Declaración sobre la libertad y la función de la teología en la Iglesia, firmada por treinta y ocho teólogos ${ }^{38}$. Constaba de un breve preámbulo y siete sintéticos puntos. Entre los firmantes se encontraban algunos de los peritos que habían intervenido en el Concilio Vaticano II y que después habían sido ponentes en el ya mencionado Congreso Internacional de Teología de 1966, y también los fundadores de la revista Concilium: Roger Aubert, Alfons Auer, Franz Böckle, Pierre Benoit, Marie-Dominique Chenu, Yves-Marie Congar, Christian Duquoc, Heinrich Fries, Walter Kasper, Hans Küng, Karl Lehmann, Johannes Baptist Metz, Karl Rahner, Joseph Ratzinger, Edward Schi-

\footnotetext{
36 Cfr. supra nt. 31.

37 FERnÁndeZ, A., «La diferencia entre el sacerdocio común de los fieles y el sacerdocio ministerial en los debates conciliares del Vaticano II», Scripta Theologica 1 (1969) 493-504.

38 En francés, en diciembre de 1968; en otras ediciones, en enero de 1969.
} 
llebeeckx, Piet Schoonenberg, etc. Con posterioridad otros teólogos se adhirieron a la carta.

En el preámbulo, los firmantes temían una involución de la libertad de investigación, que, según decían, había sido recuperada por el Concilio Vaticano II $^{39}$. Los firmantes eran conscientes de que podían errar en sus trabajos, pero exigían que no se empleasen medios autoritarios o coercitivos para corregirlos, sino el diálogo y la discusión científica. Respetaban el magisterio pontificio y episcopal, pero reclamaban un lugar propio del oficio teológico en el seno de la Iglesia ${ }^{40}$. Solicitaban que la Congregación para la Doctrina de la Fe respetase la pluralidad teológica, que los miembros de esa Congregación no superasen la edad de 75 años, que los consultores de ella fuesen elegidos entre especialistas reconocidos de distintos países, y que se constituyese de inmediato la Comisión Teológica Internacional, pedida por la primera Asamblea Plenaria del Sínodo de los Obispos, de 27 de octubre de 1967. También sugerían criterios procesales en el caso de que se abriese una investigación sobre la ortodoxia de un teólogo, entre ellos, que se nombrase siempre un defensor del autor investigado («relator pro auctore»), que no hubiese nada secreto en el proceso y que las opiniones analizadas se hiciesen sobre el original y no sobre traducciones no autorizadas por el investigado.

Aunque la carta provocó sorpresa y desagrado en la Santa Sede, algunas de las peticiones fueron atendidas de inmediato, como, por ejemplo, la creación de la Comisión Teológica Internacional, el 1 de mayo de 1969, en la que entraron tres de los firmantes (Congar, Rahner y Ratzinger). Asimismo, algunos temas sugeridos por la carta fueron estudiados por esa Comisión Teológi-

39 «In perfetta lealtà e fedeltà sincera verso la chiesa cattolica, i teologi firmatari si vedono costretti ed obbligati ad attirare apertamente e nel modo più serio l'attenzione sul fatto che la libertà dei teologi e della teologia al servizio della chiesa, ricuperata dal concilio Vaticano II, non dev'essere rimessa in pericolo oggi» (Dichiarazione sulla libertà e la funzione della teologia nella Chiesa [gennaio 1969], preámbulo, en http://www.viandanti.org/? p=416 [consulta 29-VI-2017]).

$40 \ll$ E siamo ben coscienti del fatto che noi pure teologi possiamo ingannarci nella nostra teologia. Ma siamo del pari persuasi che talune concezioni teologiche errate non potrebbero essere corrette attraverso misure coercitive. Nell'epoca in cui viviamo esse non potrebbero essere efficacemente corrette se non attraverso una discussione scientifica obiettiva al riparo da costrizioni, nella quale la verità ha possibilità di vincere per la sua intrinseca forza. Noi affermiamo con convinzione l'esistenza di un magistero del papa e dei vescovi, che sotto la Parola di Dio è al servizio della chiesa e della sua predicazione. Ma sappiamo anche che questo magistero pastorale di predicazione non può né soppiantare, né impedire la missione d'insegnamento scientifico. Ogni forma d'inquisizione, per quanto sottile essa possa essere, porta pregiudizio allo sviluppo di una sana teologia e, inoltre, nuoce grandemente alla credibilità della chiesa tutta intera nel mondo d'oggi». 
ca Internacional en años sucesivos: «La unidad y el pluralismo teológico» (1972) y «Magisterio y Teología» (1975). Tal proceso de reflexión sobre la naturaleza de la ciencia teológica, debidamente acompañado por oportunos pronunciamientos del magisterio pontificio, desembocó finalmente en la Instrucción Donum veritatis sobre la vocación eclesial del teólogo, emanada por la Congregación para la Doctrina de la Fe, el 24 de mayo de 1990, que dejamos de lado, a pesar de su importancia, porque nos sitúa fuera del marco temporal de esta crónica.

De esta controversia no he hallado eco en Scripta Theologica, al menos en los primeros números. Sí, más adelante. El respetuoso silencio también es significativo.

\section{c) La encíclica Humanæ vitæ}

Uno de los momentos de mayor confrontación entre la teología académica y el magisterio pontificio, fue la publicación de la encíclica Humane vite, en julio de 1968. Pablo VI se había reservado a sí mismo, o sea, a su suprema potestad, decidir sobre la delicada cuestión de la contracepción. Antes de pasar a las reacciones, recordemos someramente los acontecimientos ${ }^{41}$.

El 15 de febrero de 1960 la «Food and Drug Administration» (FDA) aprobó en los Estados Unidos de América el uso del Enovid como anticonceptivo, y desde ese momento su empleo se extendió por todo el mundo, planteando numerosos interrogantes a la teología moral (poco antes, y con el nombre de Enavid, se había comercializado en Inglaterra). Juan XXIII constituyó la «Comisión para el Estudio de la Población. Familia y Natalidad», que Pablo VI confirmó y amplió. Las conclusiones de esa comisión llegaron en forma de un documento ( $\ll$ Documentum syntheticum de moralitate regulationis nativitatum»). Como no todos los miembros de la comisión estaban de acuerdo con ese dictamen, el texto pasó a denominarse «informe de la mayoría», frente a otro «informe de la minoría», es decir, de los discrepantes a la autorización de la píldora.

El informe de la mayoría, fechado el 27 de mayo de 1966, fue redactado por el presbítero Philippe Delhaye, belga, profesor de la Université de Louvain-la-Neuve, que después de la encíclica se desdijo y aceptó el magisterio

${ }^{41}$ Cfr. Fernández, A., La reforma de la teología moral. Medio siglo de historia, Burgos: Aldecoa, 1997, 119-127. 
pontificio; Josef Fuchs, jesuita alemán, profesor de la Universidad Gregoriana; y Raymond Sigmond, dominico húngaro, entonces rector del Angelicum (Pontificia Universidad de Santo Tomás, en Roma). El informe de la minoría lleva las firmas del jesuita español Marcelino Zalba Erro, profesor de la Gregoriana; del jesuita norteamericano John Cuthbert Ford, profesor de la Gregoriana y después del Boston College; del jesuita francés Stanislas de Lestapis; y del teólogo redentorista holandés Jan Visser, profesor del Ateneo Alfonsiano de Roma.

Basándose en el informe de la minoría, y con la intervención destacada de algunos teólogos de confianza de Pablo VI, como el obispo Carlo Colombo, los jesuitas Gustave Martelet y Marcelino Zalba, y especialmente el franciscano Ermenegildo Lio, profesor del Lateranum, el Papa promulgó la encíclica Humance vite (HV), el 25 de julio de 1968. La encíclica estableció dos principios, uno de carácter general y otro relativo al tema debatido.

Ante todo, el Papa declaró que: «ningún fiel querrá negar que corresponda al magisterio de la Iglesia el interpretar también la ley moral natural» (HV, n. 4). En otros términos: que el magisterio pontificio no sólo se extiende a cuestiones dogmáticas o de fe, sino que llega también a los temas relativos a la vida moral, muy en particular a aquellas materias que se refieren a la «ley moral natural». Esta declaración implica, como es obvio, que hay ley natural, un asunto que fue muy discutido por los moralistas que rechazaron las disposiciones de la Humance vite.

Pasaba después a considerar un criterio básico de la vida matrimonial: la inseparabilidad de la unión de los esposos y de la procreación. Y finalmente la encíclica enseñaba:

«Hay que excluir [...], como el Magisterio de la Iglesia ha declarado muchas veces, la esterilización directa, perpetua o temporal, tanto del hombre como de la mujer; queda además excluida toda acción que, o en previsión del acto conyugal, o en su realización, o en el desarrollo de sus consecuencias naturales, se proponga, como fin o como medio, hacer imposible la procreación» $(\mathrm{HV}$, n. 14).

Pocas horas después de su presentación a la prensa (era el 29 de julio), unos veinte teólogos de la Universidad Católica de Washington redactaron la primera declaración pública de protesta, inspirada por Charles Curran, profesor de ese claustro académico. En un abrir y cerrar de ojos la suscribieron más de seiscientos teólogos norteamericanos. No pasó mucho tiempo y les tocó el 
turno a los médicos y capellanes de la Universidad Católica de Lille (Francia), que dirigieron una carta abierta a La Croix. El 5 de septiembre el Katholikentag divulgó las dudas y perplejidades de los católicos alemanes. El 19 de septiembre una asamblea de teólogos europeos reunidos en Ámsterdam elaboró un comunicado oficial para denunciar el presunto carácter anticonciliar de Humance vite. Pero las contestaciones no se ciñeron sólo a los círculos de intelectuales. En enero de 1969 la Iglesia holandesa al completo, es decir, reunida en concilio pastoral, expresaba su solidaridad con los «muchos católicos, creyentes íntegros y competentes, que no consideran que sea justo la condena [del uso de anticonceptivos] y que por tanto la rebaten con argumentos sólidos» ${ }^{42}$. Basten estos ejemplos para advertir el alcance de la protesta, porque la hubo en todas partes.

El argumento principal del informe de la mayoría se apoyaba en el «principio de totalidad», según el cual, toda acción moral debe ser juzgada en el marco de la totalidad de la vida de una persona. Si una persona se ajusta de ordinario a los principios morales principales de la vida cristiana, aunque en actos aislados no se comporte según esos principios fundamentales, esos actos no pueden considerarse inmorales o pecaminosos, porque no alteran la opción fundamental asumida. Así formulado, el «principio de totalidad» era (y es) ajeno a la tradición moral de la Iglesia, porque olvida que la fuente principal de la moralidad es la obra misma realizada (el finis operis), sin excluir, por supuesto, el fin del agente (finis operantis), el cual nunca puede hacer buena una obra intrínsecamente mala, y sí, en cambio, puede hacer mala, por la intención, una obra buena. Hay que sostener, siempre y en todo caso, que caben obras intrínsecamente malas, cualesquiera que sean la intención del agente y las circunstancias.

Para rastrear las raíces de este clima generalizado de protesta, parece oportuno remontarse a los años treinta, en que se difundió la «ética de situación» en ámbitos protestantes, por influencia de la hermenéutica existencial alemana (respaldada por el historicismo) y del análisis psicológico profundo de matriz austriaca. Después de la Segunda Guerra Mundial, la ética de situación fue acogida por muchos moralistas católicos, sobre todo alemanes, para resolver determinadas cuestiones difíciles, principalmente en el ámbito de la moral

42 Para una historia de la redacción de la encíclica (con testimonios de varios actores), cfr. http:// www.conoze.com/marco.php?doc=8378 (consulta 14-VII-2017), que tengo a la vista cuanto redacto estas líneas. Se trata de un informe sereno y muy documentado. 
matrimonial. Ellos defendían que la moralidad de las relaciones conyugales debía juzgarse principalmente por las condiciones particulares de los esposos.

La ética de situación facilitó la recepción del llamado principio de totalidad, y abrió paso, como ya se ha dicho, a la crítica de la encíclica Humane vite. Se afirmó, por parte de muchos, que los actos conyugales contraceptivos singulares quedaban justificados por una vida matrimonial en su conjunto abierta a la vida.

Por su notoriedad, cabe destacar la apuesta crítica contra la encíclica del ya referido Charles Curran, del presbítero suizo Franz Böckle, profesor en la Universidad de Bonn, y sobre todo del redentorista alemán Bernhard Häring, del Ateneo Alfonsiano de Roma.

Este tema interesó mucho a los docentes de la Facultad de Teología de Navarra. Recuerdo, porque fui testigo directo, un intenso seminario de profesores (en varias sesiones), dirigido por el Prof. Josef Ziegler, de la Universidad de Maguncia. En todo caso, hay un detenido trabajo de Ildefonso Adeva, publicado en esas fechas en Scripta Theologica, que testifica la atención con que se siguió el curso de los acontecimientos ${ }^{43}$.

\section{d) Crisis del apostolado jerárquico}

El cuadro de «disenso» que acabo de describir (es decir, la confrontación de los teólogos profesionales con el magisterio pontificio y el rechazo de $\mathrm{Hu}$ mane vite), quedaría incompleto sin unas pinceladas sobre la crisis del apostolado jerárquico.

El decreto conciliar Apostolicam actuositatem, de 18 de noviembre de 1965, reconoce la libertad de los laicos para asociarse y organizarse en sus actividades apostólicas, aunque «guardada la sumisión debida a la autoridad eclesiástica», es decir, a la jerarquía eclesiástica (AA, n. 19). Insiste así mismo en la «acción común», la «cooperación» y la «estrecha unión de las fuerzas para conseguir todos los fines del apostolado moderno y proteger eficazmente sus bienes» (AA, n. 18). En tal contexto, el decreto dedica un largo epígrafe a la Acción Católica, definiéndola, según la tradición inaugurada por Pío XI, «como la cooperación de los laicos en el apostolado jerárquico» (AA, n. 20). Esta forma de apostolado u otras semejantes (quizá se pensaba en la JOC u otros movimientos especializados de la Acción Católica), que «desarrollan en

43 ADEVA-MarTín, I., «Literatura teológica española sobre la moralidad matrimonial desde 1960 hasta la encíclica "Humanæ vitæ"», Scripta Theologica 1 (1969) 507-537. 
nuestro tiempo un apostolado precioso», se constituyen, decía el Concilio, por la aceptación conjunta de cuatro notas: $1^{\mathrm{a}}$ ) el fin inmediato de tales organizaciones es el fin apostólico de la Iglesia; $2^{\mathrm{a}}$ ) los laicos, cooperando con la jerarquía, según su condición (es decir, como laicos), se responsabilizan en la dirección de esas organizaciones; $3^{\text {a }}$ ) los laicos trabajan unidos a manera de cuerpo orgánico; y $4^{\mathrm{a}}$ ) los laicos laboran bajo la dirección superior de la misma jerarquía, «que puede sancionar tal cooperación incluso con un mandato explícito».

Obsérvese la insistencia en la «pastoral de conjunto» (un sintagma acuñado en aquellos años) entre jerarquía y laicos, bajo el control de la jerarquía, aunque salvada la libertad de asociarse. El decreto insistía en que «a fin de promover el espíritu de unidad, para que resplandezca la caridad fraterna en todo el apostolado de la Iglesia, para que se consigan los fines comunes y se eviten las emulaciones perniciosas, se requiere el mutuo aprecio de todas las formas de apostolado de la Iglesia [aquí se incluyen también los institutos seculares de los que se ha hablado en el número anterior de AA] y una coordinación conveniente, conservando el carácter propio de cada una» (AA, n. 23).

El difícil equilibrio entre la libertad de asociación y la libertad apostólica, recomendadas por Apostolicam actuositatem, y la defensa de la estricta dirección jerárquica del apostolado seglar (en la cúspide de la pirámide el obispo, en la base, los laicos), que también sostiene el decreto conciliar, provocó la crisis de la Acción Católica. Aunque no fue la única causa, sí fue una de las principales. En todo caso, en el inmediato postconcilio se produjo un éxodo masivo de militantes, tanto en Italia y España, como también en otros países donde estaba bien implantada, como Francia.

En España, la tensión entre la jerarquía y los movimientos especializados se intentó apaciguar con la redacción de unos nuevos estatutos, aprobados por la Asamblea Plenaria de la Conferencia Episcopal, en 1967. Sin embargo, el resultado no fue el esperado. A la crisis del modelo histórico de la Acción Católica se sumó tanto la pérdida de la identidad cristiana de muchos militantes, muy influidos por el «marxismo de rostro humano», que dominaba el panorama cultural español del momento, como la pérdida de identidad eclesial de esos mismos movimientos, que se politizaron en extremo, a modo de sindicatos y partidos políticos, entonces prohibidos por el régimen político del general Francisco Franco ${ }^{44}$.

${ }^{44}$ Cfr. Montero García, F., La Acción Católica y el franquismo. Auge y crisis de la Acción Católica especializada, Madrid: UNED, 2000. 
En Italia, la desbandada de militantes fue impresionante: de tres millones de afiliados en 1962, se pasó a poco más de setecientos mil en 1969. Para frenar la crisis se procedió a la redacción de unos nuevos estatutos, aprobados en 1969, en los que se incorporó la llamada «opción religiosa». Tal opción significaba un distanciamiento de la política entendida como instrumento de la religión, pero no implicaba una desvalorización de la política, que ahora quedaba confiada a la responsabilidad autónoma de los cristianos. Una serie de acontecimientos posteriores minaron más todavía la Acción Católica italiana, entre ellos el referéndum sobre el divorcio civil, que tuvo lugar a mediados de 1974. El triunfo del divorcio se interpretó como un desinterés de los católicos, del cual habría sido responsable la nueva Acción Católica, surgida de la opción religiosa, lo cual contribuyó más todavía a su descrédito ${ }^{45}$.

También en Francia se produjo una espectacular crisis de la Acción Católica especializada, provocada, en parte, por causas sociológicas, pues la Francia de los «Treinta Gloriosos», es decir, de la década inmediata antes de la Segunda Guerra Mundial, había unificado los modos de vida y la cultura de tal manera, que el apostolado «par milieux», es decir, el apostolado especializado (por actividades profesionales o estratos sociales) había quedado seriamente cuestionado. Por otra parte, se produjo una fortísima crisis ligada a la radicalización política de los movimientos de Acción Católica que cuestionaron la validez del mandato recibido por parte de los obispos. El enfrentamiento generacional que sacudió Francia después de la guerra de Argelia y que culminó en la primavera de 1968, es una de las claves, aunque no la única. Tal crisis se cebó especialmente en las dos ramas de la Juventud de Estudiantes Cristianos (JEC y JECF) y, de rebote, en el Movimiento Rural de la Juventud Cristiana (MRJC). La crisis abocó a la dimisión en bloque de los cargos nacionales de tales asociaciones. El endurecimiento de las posturas por parte de los obispos no hizo más que constatar el abismo abierto entre militantes y jerarquía ${ }^{46}$.

El problema radicaba en una ausencia de una verdadera teología del laicado, y sin ella, quedaba manco el diálogo de la Iglesia con el mundo, tan pretendido por el Vaticano II. Este tema fue objeto de seria reflexión por parte de los docentes de la Facultad de Teología, como lo prueba la amplia

${ }^{45}$ Cfr. Chenaux, P., El Concilio Vaticano II, trad. esp., Madrid: Encuentro, 2014, 185-189.

${ }^{46}$ Cfr. Pelletier, D., La crise catholique. Religion, société, politique en France (1965-1978), Paris: Payot, 2002. 
nota de Alfredo García Suárez sobre el libro Conversaciones con Mons. Escrivá de Balaguer, publicada en Scripta Theologica, de la cual me ocuparé in extenso más adelante.

\section{e) La teología de la «muerte de Dios» y la «teología política»}

En 1963 había aparecido en Inglaterra, firmado por el obispo anglicano John A. T. Robinson, antiguo biblista de la Universidad de Cambridge, el libro Honest to God, que tuvo en su momento un gran impacto, del que no se libró España. Fue traducido al castellano en 1968, en plena puesta a punto de la Facultad de Teología.

Honest to God era el resultado de la fusión de tres corrientes, o si se quiere, el punto final de tres líneas teológicas protestantes: $1^{a}$ ) Rudolf Bultmann, con su conocida desmitificación del Nuevo Testamento, y la radicalización de la brecha entre el Jesús histórico y el Cristo de la fe, porque la historia, entendida como los hechos realmente ocurridos, carece de interés y, en algún sentido, es prácticamente inaccesible; $2^{a}$ ) Dietrich Bonhoeffer, que elaboró la más extrema presentación del cristianismo, o sea, un cristianismo a-religioso (la paradoja del cristianismo consiste en ser una fe sin religión, sólo Cristo y yo, y nada más); y $3^{\mathrm{a}}$ ) Paul Tillich, que había popularizado su concepto de «dimensión de profundidad» (la religión como una dimensión necesaria de la vida espiritual del hombre, pero como una fe sin Dios). A partir de tales premisas, Robinson se propuso reinterpretar la fe para hacerla accesible al hombre moderno. Su teología planteaba el problema de «cómo decir Dios» en un contexto de secularismo ${ }^{47}$.

Refiriéndose al grupo, realmente no homogéneo, de teólogos protestantes anglosajones, entre los cuales el más conocido era John A. T. Robinson, escribía Illanes entonces: «De los diversos nombres con que se ha dado en calificar a ese movimiento -"teología radical", "teología de la muerte de Dios", "ateísmo cristiano", "teología de la secularización"-, este último es, a mi juicio, el más adecuado, pues se refiere a la única característica que tienen en común todos ellos. Todos afirman, en efecto, que en nuestros días está llegando

47 Para una reseña histórica de la teología de la muerte de Dios, una corriente muy minoritaria, pero que la prensa de la época exageró, incluyendo en ella a muchos profesionales protestantes de la teología, véase: GiBELlini, R., La teología del siglo XX, trad. esp. de VELASCO, R., Santander: Sal Terrae, 1998, 153-157. 
a su pleno desarrollo un proceso de secularización o desacralización de la cultura y, teniendo presente ese hecho, inician su reflexión sobre el mensaje cristiano» ${ }^{48}$.

En aquellos años se discutía también en Europa sobre la categoría «mundo» y daba sus primeros pasos una teología adjetiva relativamente nueva: la teología política. Esta corriente, pilotada por el alemán Johann Baptist Metz, de la Universidad de Münster en Westfalia, pretendía asimismo exponer la fe en consonancia con el horizonte cultural del momento. Para Metz, el «mundo» era el devenir histórico. Por tal vía, reflexionando sobre la secularización, entendida ésta como situación del tránsito desde un mundo divinizado a un mundo hominizado, se llegaba a la discusión, ya teológica en sentido propio, acerca de la naturaleza de la «secularidad». La obra principal de Metz, Zur Theologie der Welt, que data de 1968, fue igualmente analizada por José Luis Illanes al poco de aparecer ${ }^{49}$.

\section{f) La teología de la liberación}

La teología de la liberación no había adquirido entonces la gran notoriedad que después alcanzó. Las tres obras que supusieron su lanzamiento se publicaron en el bienio 1971-1972, a cargo de Gustavo Gutiérrez, Ignacio Ellacuría y Leonardo Boff ${ }^{50}$. No extrañe, pues, que no hallemos nada al respecto en los primeros números de la revista de la Facultad. Sólo a partir de 1975 esa teología adquirió relieve internacional, con traducciones al alemán, inglés, francés e italiano.

En cualquier caso, el tema de fondo planteado por la liberación (cómo influye el quehacer temporal en el más allá) ya se debatía de antiguo en Europa, como secuela de las discusiones sobre el «advenimiento del Reino», provocadas por la exégesis luterana tardía. Este «teologúmeno» sí tuvo influjo (y mu-

48 ILLANES, J. L., «La secularización en la teología anglosajona», Scripta Theologica 1 (1969) 189211. Illanes pertenecía sólo de iure en el claustro académico de la Facultad, pues residía en Roma, aunque mantenía una colaboración muy estrecha con sus colegas de Pamplona. En otoño de 1977 se incorporó a la Universidad de Navarra a todos los efectos, trasladándose a vivir a Iruña.

49 Illanes, J. L., «Presupuestos para una teología del mundo. Análisis del intento teológico de Johann Baptist Metz», Scripta Theologica 3 (1971) 425-474.

50 Sobre la teología de la liberación, cfr. SARANYANA, J.-I., «Teología latinoamericanista (I)», en Saranyana, J.-I. (dir.), Alejos Grau, C. J. (coord.), Teología en América Latina, Madrid-Frankfurt: Iberoamericana-Vervuert, 2002, III, 255-365. Una versión abreviada en SARANYANA, J.-I., Breve historia de la teología en América Latina, Madrid: BAC, 2009, 287-312. 
cho) en los primeros pasos de la Facultad de Teología, como se verá a continuación, aunque en perspectiva distinta a la luterana, pietista o no.

\section{UN PROYECTO TEOLÓgICO PARA UNA NUEVA FACULTAD}

Como ya se dijo, en 1969 comenzó a publicarse Scripta Theologica, la revista de la nueva Facultad. En su presentación a los medios, García Suárez, su primer director, afirmó:

«La teología es un caminar, un estar siempre andando: es un saber peregrinante. La teología es la servidora de todas las ciencias y todos los interrogantes quieren ser captados por ella. [...]. La Teología no debe investigar al margen de las preocupaciones y cometidos humanos. No es una ciencia abstracta. Aislada de la universidad, corre el riesgo de empobrecerse, de igual modo que una Universidad resulta incompleta si está desposeída de Ciencias Teológicas» ${ }^{51}$.

Referencia importante, para conocer las ideas que manejaban los pioneros del nuevo centro académico, es la valoración que Pedro Rodríguez hizo del ya citado «Congreso de Teología del Vaticano II», de 1966. Esa evaluación certifica, en todo caso, la impresión que las sesiones causaron en Alfredo García Suárez y en Pedro Rodríguez, que participaron en esa convención juntamente con José Luis Illanes.

Veamos las cuatro conclusiones a las que llegó Pedro Rodríguez, cronista del evento:

«La primera [conclusión] -y la fundamental, a mi modo de ver, porque incluye a las demás- es el descubrimiento de la historicidad: historicidad del hombre, historicidad de la verdad, también de la verdad revelada; historicidad de la Iglesia. [...] El drama ha consistido en que esa captación ha acontecido patológicamente, al identificar historicidad con relativismo filosófico. El surgir de la conciencia histórica pareció a muchos que proporcionaba los instrumentos científicos incontrovertibles para dar al traste con la Revelación cristiana, que se presenta como absoluta. Al pasar los años, depurada de la ganga, la Iglesia no sólo acepta este fenómeno de "biología histórica" (Jesús Arellano), sino que descubre en él una sorprendente congruencia con la estructura de la Revelación, que

${ }^{51}$ Diario de Navarra, del 16 de marzo de 1969, 9. 
es histórica -la historia de la salvación-. Es precisamente desde la historicidad [...] como se puede ejercitar una verdadera comprensión de la teología tradicional, del clasicismo teológico, a la vez que se tiene la base para unas formulaciones teológicas que den razón más sintéticamente de la verdad absoluta de la Palabra de Dios. Sólo en esta perspectiva puede situarse el problema de la evolución del dogma, el tránsito de la tolerancia a la libertad religiosa, el diálogo con el mundo y una verdadera teología pastoral, por poner unos ejemplos» ${ }^{52}$.

La segunda conclusión se refiere a la afirmación del «pluralismo teológico, como una exigencia de la historicidad de la verdad y entendido, por tanto, como algo enriquecedor de la catolicidad de la Iglesia».

La tercera conclusión, «implicada también en la primera, es la idea de continuidad [...], un gran respeto a la teología precedente».

Y la cuarta conclusión era formulada por Pedro Rodríguez en los siguientes términos: «El valor del mundo y su significación en la historia de la salvación».

Recapitulemos: historicidad, pluralismo teológico, continuidad y valor del mundo. Pienso que esas cuatro notas, provenientes no sólo de una reflexión sobre el congreso de 1966, sino del espíritu recibido de san Josemaría Escrivá de Balaguer, arrojan luz sobre las ilusiones de la nueva Facultad que miraba hacia el futuro, sin quedar aprisionada por los sucesos del presente. Dediquémosles alguna atención, aunque somera.

$1^{\text {a) }}$ La discusión sobre la historicidad del dogma y de la Revelación coleaba en el ámbito académico, sin resolverse, desde la aparición del historicismo. En efecto, después de las guerras napoleónicas se abrió paso la «crítica de la razón histórica», como una lógica consecuencia de las tres «críticas» kantianas (crítica de la razón pura, crítica de la razón práctica y crítica del juicio) ${ }^{53}$.

52 RodrígueZ, P., «El Congreso de Teología del Vaticano II», cit. en nt. 26, 23-24.

53 Si las críticas kantianas afirmaban que la razón (en sus tres niveles) está condicionada, de modo que sólo hay acceso intencional al fenómeno y no al noúmeno, análogamente la crítica histórica sólo reconoció la intelección de los fenómenos provocados por los hechos, negando la posibilidad de llegar a los hechos mismos, o sea, a la historia misma. El traslado de este planteamiento a la exégesis bíblica abocó a la imposibilidad de conocer, a través del texto, los hechos históricos subyacentes al texto, que originaron el texto. 
Esta novedad afectó muy negativamente a la teología liberal (recordemos aquí a Friedrich Schleiermacher, que redujo la dogmática a pura positividad) y abrió una brecha insalvable entre los hechos históricos y la recepción o lectura de tales hechos. El historicismo, pues, no fue una simple recuperación de la historia, sino una visión crítica de la historia («crítica» en el sentido ilustrado).

Contemporáneamente comenzaba a caminar el idealismo. Y, aunque parezca una paradoja, la reivindicación del curso histórico por parte del idealismo influyó benéficamente en los teólogos católicos de Tubinga, sobre todo en Johann Adam Möhler, fallecido en 1848. Y de tal rehabilitación de la historia, sub specie catbolica, contemplada con suspicacia por la teología neoescolástica del XIX, sacó provecho finalmente toda la teología católica del siglo XX. A este tema apunta Pedro Rodríguez en su primera conclusión. (Entre paréntesis debe decirse que él era ya un gran devoto de Möhler, como también Fernando Sánchez Arjona, cuando se gestaba la Facultad de Teología de Navarra. Al cabo de los años, el profesor Rodríguez editaría, con la inestimable colaboración de su discípulo José Ramón Villar, La unidad de la Iglesia y la Simbólica, las dos obras mayores de Möhler, que a finales de los sesenta ya tenía traducidas) ${ }^{54}$.

$2^{a}$ ) Desde el punto de vista teológico, la historicidad de la teología implicaba la pluralidad teológica, asunto muy delicado a comienzos del siglo XX. Algunos habían interpretado reductivamente la encíclica leonina Eterni Patris, de 1879, como si la neoescolástica tuviese la exclusividad teológica, no sólo formal, sino también temática. La recomendación e insistencia de san Pío X en el estudio de Tomás de Aquino, se leyó sesgadamente en tal contexto, de modo que se consideró la síntesis tomasiana como un totum cristalizado, al margen de cualquier marco histórico. Por ello, los estudios históricos del tomismo, promovidos por Marie-Dominque Chenu y Étienne Gilson fueron vistos con sospecha por parte de los profesores de los ateneos romanos, hasta el extremo de condenar el programa de estudios de Le Saulchoir, expresado por Chenu en su célebre conferencia de 1936, titulada Une école de théologie: Le Saulchoir (publicada en 1937 e incluida en el Índice de libros probibidos en 1942).

La afirmación de la pluralidad teológica constituía, por lo demás, no sólo una consideración que surgía del desarrollo de las ideas vertidas en el congre-

${ }^{54}$ Möhler, J. A., La unidad de la Iglesia, ed. de Rodríguez, P. y Villar, J. R., Pamplona: EunateServicio de Publicaciones de la Universidad de Navarra, 1996; MöHLER, J. A., Simbólica, ed. de RodrígueZ, P. y Villar, J. R., Madrid: Cristiandad, 2000. 
so de 1966, sino una exigencia perentoria para los jóvenes teólogos de Pamplona. En efecto, el fundador del Opus Dei había afirmado con fuerza que el reconocimiento de la legitimidad del pluralismo en las cuestiones temporales -no sólo las políticas y culturales sino también las filosóficas y las teológicas-, siempre en el contexto de una plena fidelidad al Magisterio, era una realidad que derivaba directamente del carisma secular que inspira toda la vida del Opus Dei. Y, por tanto, la vida de la Facultad.

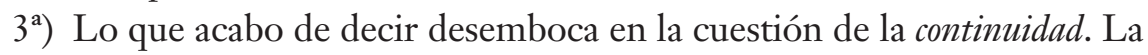
historicidad no está reñida con la continuidad, ni ésta con la pluralidad, sino todo lo contrario. Lo que ya había intuido John Henry Newman, al tratar acerca del desarrollo del dogma católico (o Francisco Marín Solá al escribir sobre la evolución homogénea del dogma católico) se podría aplicar análogamente a la evolución de la tradición teológica; algo así como una discontinuidad en la continuidad, nuevas ramas de reflexión que enriquecen la comprensión de la fe apostólica. De esta forma, cuando Pedro Rodríguez subrayaba la historicidad de la verdad, no pretendía negar el carácter absoluto de la Verdad (con mayúscula), ni la permanencia de la ley moral natural, ni la subsistencia de la naturaleza humana en sus notas esenciales a través de los tiempos, ni nada parecido; sólo quería insistir en que es histórica la comprensión de la verdad, en el sentido de que per prius la verdad está en el intelecto (es la verdad lógica), entendida como adecuación del intelecto y la cosa, y que en este proceso también influye el paso de la historia, porque el sujeto cognoscente está siempre situado, lo quiera o no.

\section{De las Relaciones del acá CON El más allá, O SEA DE LA SECULARIDAD}

\section{a) La «bomilía del campus»}

Queda por comentar la cuarta conclusión formulada por Pedro Rodríguez en su crónica sobre el congreso romano: la rehabilitación teológica del mundo. De nuevo nos encontramos con una realidad que, en la pluma del entonces joven profesor de Pamplona, hundía sus raíces mucho más allá del congreso de 1966, pues entroncaba con el núcleo del espíritu del Opus Dei.

Por ello, para glosar esta conclusión nada mejor que acudir a la homilía que san Josemaría pronunció en Pamplona, el 8 de octubre de 1967, pocos días antes de que iniciara su actividad docente el Instituto de Teología, y un 
año después del congreso vaticano ${ }^{55}$. Como ha escrito Illanes, «san Josemaría consideró que la homilía que debería pronunciar sería un buen momento no sólo para elogiar la labor de la Universidad y la ayuda que le prestaban sus amigos, sino también para realizar una exposición sintética de algunas coordenadas del espíritu del Opus Dei. A este objetivo responde de hecho la mayor parte del texto al que llegó, después de haberlo trabajado detenidamente» ${ }^{56}$.

Para el comentario de esta riquísima homilía podemos echar mano de muchos trabajos ${ }^{57}$. Entre todos, y por su proximidad a los hechos, destaca una nota que publicó Alfredo García Suárez en $1970^{58}$. Pero, veamos antes un poco de contexto teológico.

\section{b) Secularidad, mundo y Reino}

Como se ha recordado antes, al hablar de John A. T. Robinson y Johann B. Metz, durante la década de los sesenta el mundo teológico trabajó mucho para afinar algunas categorías teológicas, como «secularidad», «mundo» y «reino de Dios». La cuestión coleaba de lejos, al menos desde 1870, preparada por algunos episodios relevantes como: la campaña desatada por el Kulturkampf contra los católicos, desacreditados, además, por las tesis de Max Weber (1905) sobre el progreso humano supuestamente ligado a la Reforma; la teorización acerca del apostolado jerárquico, provocada por la aparición de la Acción Católica y de los movimientos especializados de ésta (y su corolario sobre la noción de «seglar»y la «condición sacerdotal» de éste); el problema de

${ }^{55}$ La homilía se incluye, como última pieza, en el volumen: Conversaciones con Mons. Escrivá de Balaguer, edición crítico-histórica antes citada en nota 10, supra.

${ }^{56}$ ILLANES, J. L., «La homilía de 1967 en el contexto de los escritos de san Josemaría Escrivá de Balaguer», Scripta Theologica 49/2 (2017) 455-470, aquí 465. El primer borrador de homilía fue redactado por Pedro Rodríguez, que contó con la ayuda de Alfredo García Suárez. Esta minuta estaba preparada a finales de agosto de 1967. Josemaría Escrivá corrigió y reelaboró muy a fondo el primer borrador, en Elorrio (Vizcaya) y después en Madrid, durante las jornadas anteriores a su traslado a Pamplona, donde fue leída, como ya se ha dicho, el 8 de octubre de 1967. Los nn. 118-120 (sobre la naturaleza secular de los fieles del Opus Dei y de las labores apostólicas que promueven) fueron incorporados durante esa revisión, a petición de Escrivá, y redactados por García Suárez. Cfr. Conversaciones con Mons. Escrivá de Balaguer, edición crítico-histórica, cit., 70-71.

${ }^{57}$ Cfr. una amplia relación bibliográfica sobre la homilía, en la edición crítica citada de Conversaciones, 49, nt. 111.

58 GarCía SuÁREZ, A., «Existencia secular cristiana. Notas a propósito de un libro reciente», Scripta Theologica 2 (1970) 145-164. 
la confesionalidad de los partidos y movimientos políticos, que venía de los años veinte (sobre todo en Francia) y que había abocado a una desigual recepción de las tesis de Jacques Maritain, de 1936; la erección de la Misión de Francia en 1941, la posterior Misión de París y la aparición de los sacerdotes obreros; el clamor pro libertad religiosa, entendida como derecho civil, enfrentada a la mera tolerancia, especialmente en los Estados Unidos de América; y, finalmente y ya en el inmediato postconcilio, la crisis de la Acción Católica en Francia, España e Italia.

Los acontecimientos reseñados (se podrían citar más todavía), que habían hecho correr mucha tinta y provocado grandes debates, exigían soluciones teoréticas nuevas. Y esto es justamente lo que aportó la citada homilía del campus, como destacaba García Suárez en su comentario de 1970. Algunas frases suyas, al hilo del texto homilético, resultan muy aclaratorias ${ }^{59}$.

Aproximándose al sistema eclesiológico que allí se refleja, dice García Suárez:

«Para fijar un punto de partida que permita posteriores análisis, una primera aproximación al tema [de la secularidad] podría hacerse sobre la base de estas palabras del autor [Escrivá de Balaguer]: "allá donde hay un cristiano que se esfuerza por vivir en nombre de Jesucristo, allí está presente la Iglesia" (Conversaciones, 112c). Tal vez bajo esta frase se descubra la tesis básica del sistema [eclesiológico] a que me refería, sobre todo si se explicita en términos formales como podría hacerse a través de la siguiente traducción: la Iglesia de Cristo no se resuelve en (o no se identifica con) sus elementos jerárquicos. $\mathrm{O}$ también mediante otra versión equivalente, en última instancia, a la anterior: los creyentes no cualificados jerárquicamente -los simplices christifideles- hacen presente la Iglesia en virtud de su misma existencia (auténtica) cristiana. Por supuesto, no hay duda alguna de que la existencia cristiana connota de suyo -en sus mismos factores definitorios- una relación al ministerio jerárquico. [...] Pero la cuestión imbricada en la formulación de que partimos no versa sobre la realidad de esta relación que es, para el ser cristiano, de orden constitutivo» ${ }^{60}$.

${ }^{59}$ A veces García Suárez toma alguna expresión de la entrevista concedida por Josemaría Escrivá a L'Osservatore de la Domenica, que se publicó en mayo de 1968, en tres entregas, y que se incluye asimismo en el volumen Conversaciones.

${ }^{60}$ GarCía SuÁreZ, A., «Existencia secular cristiana. Notas a propósito de un libro reciente», 146. 
Y acto seguido viene la principal consecuencia:

«Lo que la questio plantea es si puede darse una presencia de la Iglesia de Cristo en el mundo sin que se dé, al mismo tiempo, una presencia del ministerio jerárquico qua talis, al menos por vía de participación [referencia clara a la Acción Católica como participación de los seglares en el apostolado jerárquico]. Pues bien, la idea de que la realización de la existencia cristiana bic et nunc hace presente a la Iglesia, pero no hace presente al ministerio eclesiástico, es, a mi entender, el eje central en torno al cual se desarrollan, como en círculos concéntricos, los temas más importantes de este libro [Conversaciones]. $\mathrm{Al}$ autor le interesa hacer patente que la existencia secular cristiana (es decir, la existencia secular vivida con autenticidad por un cristiano) es portadora de vigor eclesial y, por ello, realizadora del Reino de Dios en la medida en que la Iglesia peregrina puede anticiparlo. "Lo específico de la vocación laical" (Conversaciones, 59d) es, para Escrivá de Balaguer, el cristianismo vivido secularmente, el testimonio connatural a la fe y a las energías vitales cristianas, ejercido in seculo y ex seculo, sin que incidan, en este dinamismo modalidades nuevas de testimonios sobreañadidos, bien procedan éstos de una participación en el ministerio jerárquico, bien de la decisión de radicalizar en la propia vida las dimensiones escatológicas cristianas (testimonio de la consecratio religiosa) ${ }^{61}$.

\section{UN SEXENIO RICO, DIFÍCIL Y FELIZ}

He pretendido ilustrar, a lo largo de estas páginas, que sólo en seis años, desde 1966, en que comenzó a perfilarse la base programática de la nueva Facultad, hasta 1972, en que ya estaban activos los dos ciclos de estudios (licenciatura y doctorado), establecidas las tres secciones, lanzada la revista Scripta Theologica e iniciada la nueva colección de monografías teológicas, la Facultad soltó amarras, salió de puerto y comenzó a navegar a ritmo de crucero.

El 26 de junio de 1975 se produjo un hecho inesperado y muy doloroso: el repentino fallecimiento de san Josemaría Escrivá, que había ideado todo el proceso, y lo había alentado y sostenido. El beato Álvaro del Portillo, su sucesor, continuó fielmente la tarea emprendida y la amplió, llevando a término algunos proyectos que san Josemaría no pudo culminar.

${ }^{61}$ Ibid., 146-147. 
Pronto vino la construcción de un edificio propio en el campus de la Universidad (inaugurado en octubre de 1976); el comienzo de los «simposios internacionales de teología» (desde abril de 1979); la adecuación de la Facultad a la nueva legislación eclesiástica, que comportó la inauguración del ciclo institucional (en octubre de 1981); los nuevos estatutos de la Facultad (aprobados por la Congregación de Educación Católica ad experimentum el 5 de julio de $1983)^{62}$; la puesta en marcha de unas extensiones en Roma, que constituyeron el embrión de la Pontificia Università della Santa Croce, hoy realidad espléndida; etc.

Pero de todo esto, quien mejor podría dar testimonio, por haber sido protagonista directo desde otoño de 1977, es el Prof. José Luis Illanes. Por ello termino aquí mi relato, con un gran agradecimiento a los que ya no están, por el esfuerzo que pusieron en la empresa, y a Dios, muy en particular, que nunca nos dejó de su mano.

${ }^{62}$ La aprobación definitiva de los estatutos tuvo lugar el 14 de abril de 1987. 


\section{Bibliografía}

ADEVA-MARTÍN, I., «Literatura teológica española sobre la moralidad matrimonial desde 1960 hasta la encíclica "Humanæ vitæ"», Scripta Theologica 1 (1969) 507-537.

Calvo de las Fuentes, J. Ma (ed.), Teología y Universidad. En el XXV aniversario de la Facultad de Teología de la Universidad de Navarra (1967-1992), Pamplona: Servicio de Publicaciones de la Universidad de Navarra, 1993.

Chenaux, Ph., El Concilio Vaticano II, trad. esp., Madrid: Encuentro, 2014.

Dichiarazione sulla libertà e la funzione della teologia nella Chiesa (gennaio 1969), preámbulo, en http://www.viandanti.org/?p=416 [consulta 29-VI-2017]).

Escrivá de Balaguer, J., Conversaciones con Mons. Escrivá de Balaguer, edición crítico-histórica a cargo de ILLANES, J. L. y MÉNDIZ, A., Madrid: Rialp, 2012.

FERNÁNDEZ, A., «La diferencia entre el sacerdocio común de los fieles y el sacerdocio ministerial en los debates conciliares del Vaticano II», Scripta Theologica 1 (1969) 493-504.

FERNÁNDEZ, A., La reforma de la teología moral. Medio siglo de historia, Burgos: Aldecoa, 1997.

Fuenmayor, A. DE, Gómez-IGlesias, V. e Illanes, J. L., El itinerario jurídico del Opus Dei. Historia y defensa de un carisma, Pamplona: Eunsa, 1989.

García SuÁrez, A., «Existencia secular cristiana. Notas a propósito de un libro reciente», Scripta Theologica 2 (1970) 145-164.

GibellinI, R., La teología del siglo XX, trad. esp. de Velasco, R., Santander: Sal Terrae, 1998.

GonZÁlez Gullón, J. L., DYA. La Academia y Residencia en la bistoria del Opus Dei (1933-1939), Madrid: Rialp, 2016.

Grossmann, A. y LANDMEsser, Ch. (eds.), Rudolf Bultmann / Martin Heidegger. Correspondencia. 1925-1975, trad. esp. de GABÁs, R., Barcelona: Herder, 2011.

ILlaNES, J. L., «La homilía de 1967 en el contexto de los escritos de san Josemaría Escrivá de Balaguer», Scripta Theologica 49 (2017) 455-470.

Illanes, J. L., «Mons. Álvaro del Portillo y las Facultades de ciencias eclesiásticas de la Universidad de Navarra», Scripta Theologica 46 (2014) 697-718.

ILLANES, J. L., «Presupuestos para una teología del mundo. Análisis del intento teológico de Johann Baptist Metz», Scripta Theologica 3 (1971) 425-474.

ILlaNES, J. L., «Teología y método teológico en los documentos del Concilio Vaticano II», Scripta Theologica 12 (1980) 761-787. 
Illanes, J. L., Teología y Facultades de Teología, Pamplona: Eunsa, 1991.

LosAdA EsPinosa, J., «Congreso Internacional del Concilio Vaticano II», Razón y Fe 174 (1966) 455-466.

MöHler, J. A., La unidad de la Iglesia, ed. de Rodríguez, P. y Villar, J. R., Pamplona: Eunate-Servicio de Publicaciones de la Universidad de Navarra, 1996.

Möhler, J. A., Simbólica, ed. de Rodríguez, P. y Villar, J. R., Madrid: Cristiandad, 2000.

Montero García, F., La Acción Católica y el franquismo. Auge y crisis de la Acción Católica especializada, Madrid: UNED, 2000.

Morales, J., «Nota histórico-doctrinal sobre las relaciones entre magisterio eclesiástico, oficio teológico y sentido popular de la fe», Scripta Theologica 2 (1970) 481-499.

Nuevo Catecismo para adultos. Versión integra del catecismo bolandés, Barcelona: Herder, 1969; Suplemento al Nuevo Catecismo para adultos. Enmiendas y adiciones al Catecismo holandés, redactadas según las indicaciones de la Comisión Cardenalicia, Barcelona: Herder, 1969; Las correcciones al Catecismo bolandés. Suplemento al Nuevo Catecismo, texto redactado por DHANIs, É., VISSER, J. y Fortmann, H. J., Madrid: BAC, 1969 (con complementos de Pozo, C.).

Pelletier, D., La crise catholique. Religion, société, politique en France (19651978), Paris: Payot, 2002.

Requena, F. M., «El claustro académico de Estudios Eclesiásticos de la Sociedad Sacerdotal de la Santa Cruz: los profesores de Teología de Álvaro del Portillo», Studia et Documenta 9 (2015) 13-55.

Rodríguez, P., «El Congreso de Teología del Vaticano II», Palabra 15 (1966) 19-24.

RodríGueZ, P., «Misterio y comunidad. Estudio de sus relaciones en orden a la fundamentación de una teología del ministerio eclesiástico», Scripta Theologica 2 (1970) 119-142.

SARANYANA, J.-I., «Teología latinoamericanista (I)», en SARANYANA, J.-I. (dir.), Alejos Grau, C. J. (coord.), Teología en América Latina, Madrid-Frankfurt: Iberoamericana-Vervuert, 2002, III, 255-365.

SARANYANA, J.-I., Breve historia de la teología en América Latina, Madrid: BAC, 2009. 